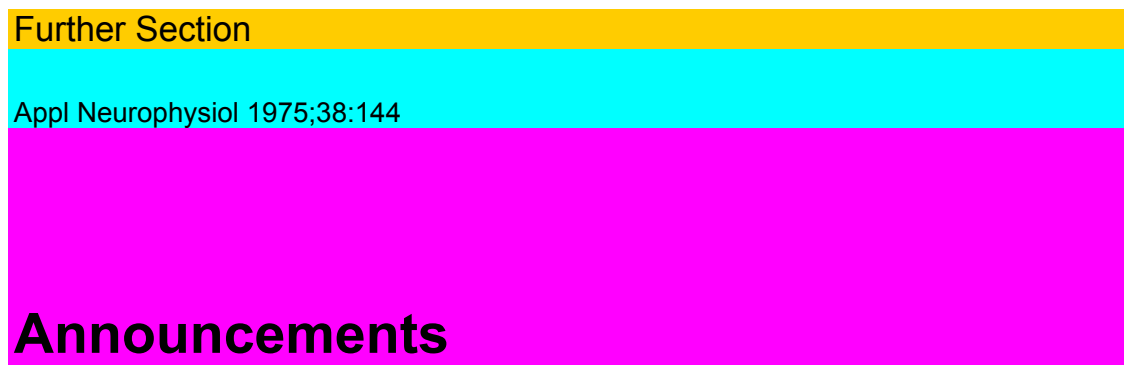

\title{
Annual Houston Neurological Symposium
}

The Annual Houston Neurological Symposium, sponsored by the University of Texas Health Science Center at Houston - Medical School, will deal with 'Basic and Clinical Aspects of Neurotransmitter Function'.

The meeting will be held March 11-13, 1976 at the Marriot Hotel at 2100 South Braeswood, Houston, Texas. For registration information, please contact: WiLLIAM S. FILEDS, MD, Director, Program in Neurology, University of Texas Medical School, 6301 Almeda, Houston, TX 77021 (USA).

\section{Third Course in Clinical Neuro-Otolaryngology}

University of Pittsburgh School of Medicine, Eye and Ear Hospital of Pittsburgh, Pittsburgh, Pa.

The course is designed for practitioners of otorhinolaryngology or neurology and residents in training, to aid in the understanding of the various neurological aspects of otorhinolaryngological disorders. The focus will be on practical clinical evaluation and management.

Topics covered will include the function, clinical evaluation, and disorders of the vestibular system, audition, taste, olfaction, speech, swallowing, and the facial nerve. The course is acceptable for AMA credit hours in category 1.

For further information, please write to: SIDNEY N. BUSIS, MD, Course Director, Eye and Ear Hospital of Pittsburgh, Pittsburgh, PA 15213 (USA). 